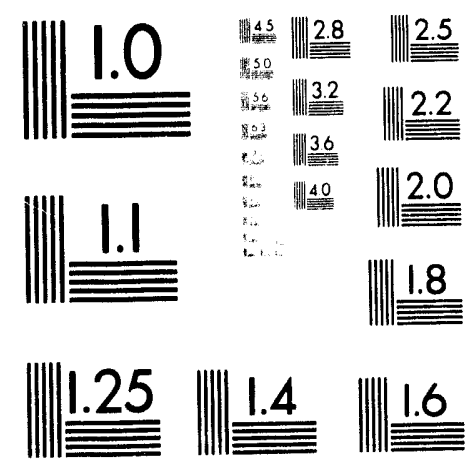



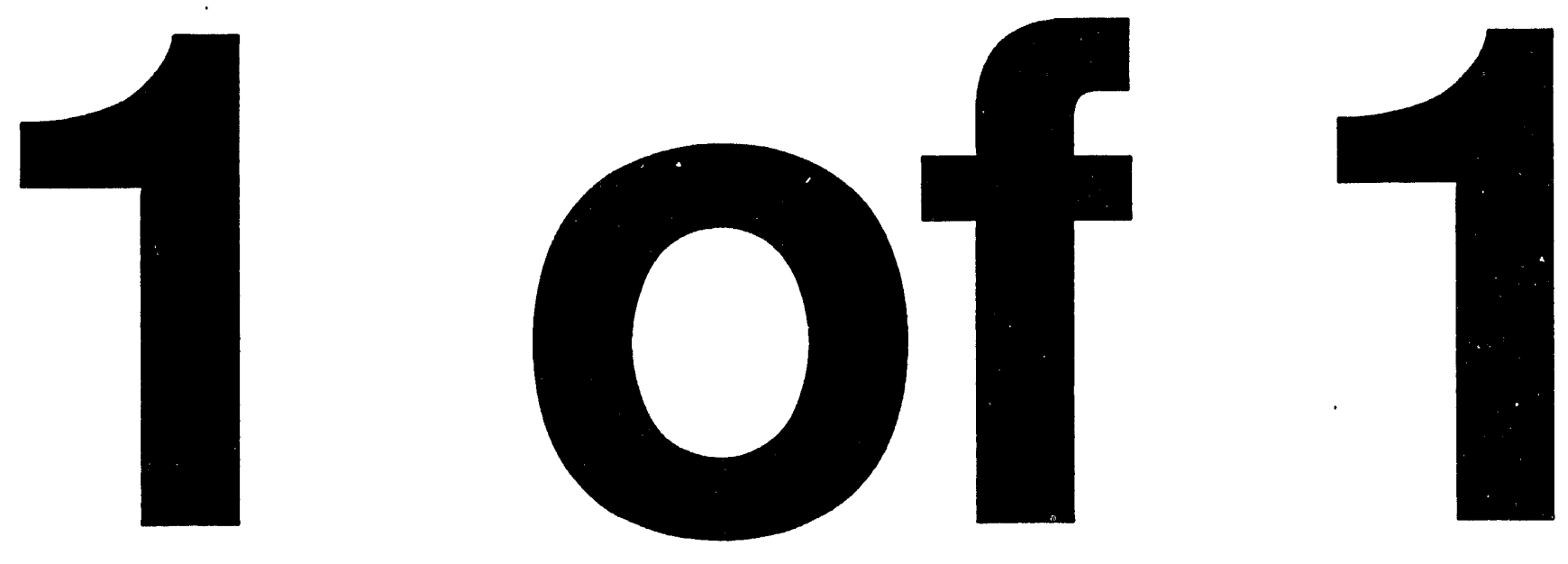
LBL-33475

L-169

\title{
Considering Lighting System Performance and HVAC Interactions in Lighting Retrofit Analysis
}

\author{
Ellen Franconi and Francis Rubinstein \\ Energy and Environment Division \\ Lawrence Berkeley Laboratory \\ University of California \\ Berkeley, California 94720
}

October 1991

\section{MASTER}

This work was supported by the Assistant Secretary for Conservation and Renewable Energy, Office of Building Technologies, Building Equipment Division and the Deputy Undersecretary of the Office of Policy, Planning, and Analysis, through the U.S. Department of Energy under Contract No. DE-AC03-76SF00098. 
Considering Lighting System Performance and HVAC Interactions in Lighting Retrofit Analysis

\author{
Ellen Franconi and Francis Rubinstein* \\ Energy Analysis Program \\ *Building Technologies Program \\ Energy \& Environment Division \\ Lawrence Berkeley Laboratory \\ Berkeley, California 94720
}

October 1991

This work was supported by the Assistant Secretary for Conservation and Renewable Energy, Office of Building Technologies, Building Equipment Division and tyhe Deputy Undersecretary of the Office of Policy, Planning, and Analysis through the U.S. Department of Energy under Contract No. DE-ACO3-76SFOOO98. 


\title{
Considering Lighting System Performance and HVAC Interactions in Lighting Retrofit Analyses
}

\author{
Ellen Franconi ${ }^{*}$ and Francis Rubinstein ${ }^{\dagger}$ \\ *Energy Analysis Program \\ †Building Technologies Program \\ Energy \& Environment Division \\ Lawrence Berkeley Laboratory \\ Berkeley, California 94720
}

\begin{abstract}
The performance of several typical fluorescent lighting retrofits are examined using analysis methods of varying sophistication. Estimates of energy and lighting performance based on the simple non-application specific data generally available tend to overestimate the energy savings obtained with the varlous retrofits by 10 . $30 \%$. Adding a simple correction to account for cooling benefits exacerbates the error unless heating penalties are also considered. An analysis method that takes into account the thermal application factor of the lighting system shows that the error is typically due to systematically overestimating the energy usage of the original lighting system. If thermal application factor is considered, then detailed HVAC calculations do not significantly improve the energy-savings estimate.
\end{abstract}

\section{INTRODUCTION}

Retrofitting the lighting systems in existing buildings with new energy-efficient lamps and ballasts has the potential to significantly reduce the energy consumption of the U.S. building stock. Ideally, the most appropriate and costeffective retrofit technologies would be identified by accurately analyzing the building energy use before and after the proposed retrofit. Such an analysis would be useful not only for a firm seeking to maximize its investment in energyefficient lighting but also for utility demand side managers needing to better understand the impact of lighting retrofits on the utility's demand profile. However, precise energy analysis is rarely performed because of the difficulty in obtaining appropriately specific performance data for the building lighting system under examination.

Accurate lighting energy analysis must consider the fact that fluorescent lighting systeins, which dominate in commercial buildings, are complex, temperature-sensitive systems that consist of many components. A fluorescent luminaire consists of lamps, ballasts, and a fixture that is integrated into the building ceiling system in a particular manner.
While performance data are available for the system components under a standardized set of test conditions (referred to herein as the ANSI conditions), limited performance data are available for the components operating as a system. It is well known that the light output and power consumed by a given fluorescent lamp/ballast combination varies with the temperature of the lamp $[1,2]$. Thus, different fixture designs will result in different lamp operating temperatures and therefore different system performances. Conventional luminaire photometry captures some of these thermal effects. However, in a lighting retrofit, it is rare for the specifier to have the photometric test for the particular lamp/ballast/fixture system of interest. As a result, the specifier resorts to manufacturers' data combined with standard assumptions about the system's performance to choose between various fluorescent retrofit options. These data and assumptions can lead to significant errors in predicting the energy savings and post-retrofit light levels.

Indeed, even if photometric reports are available for the specific lamp/ballast/fixture combinations under consideration, it is unlikely that performance will be accurately predicted because the luminaire manufacturer's data is gathered under test conditions that may represent a significantly different thermal environment than that encountered in the field. That is, conventional photometry does not address the difference in performance between the luminaire test condition and the specific application condition. Several researchers have recommended including an application thermal factor into the standard lumen calculations [3] ; however, little data is available for these factors.

Finally, even with lighting performance evaluated with application specific data, predicted energy savings from lighting retrofits may not represent actual energy savings due to the lighting system interaction with the building heating, ventilation, and air conditioning (HVAC) system. Thus, from the broadest perspective, an accurate forecast of the change in energy use should also consider how the change in lighting power affects the energy used for cooling and heating the building.

Yet how critical are system performance, application conditions and HVAC interactions to the accurate prediction 
of lighting energy savings in buildings? More importantly, which of these uncertainties have the biggest impact on our ability to predict post-retrofit performance? In this paper, we compare lighting performance and retrofit savings determined using different analysis methods -- a standard method and a more application specific method.

\section{METHODS}

We have selected a typical large open-office space equipped with standard fluorescent fixtures as the basis of our lighting analyses. The office space covers 5000 square feet with dimensions of $100^{\prime}$ by $50^{\prime}$ with a $9.5^{\prime}$ ceiling height. The lighting system is comprised of 45 recessed-mounted ceiling fixtures, spaced $8^{\prime} \times 10^{\prime}$ on center. Each $2^{\prime} \times 4^{\prime}$ fixture has a prismatic lens and houses 4 standard cool white lamps and two standard magnetic ballasts. Typical reflectivities are assumed $-.8, .5$, and .2 for the ceiling, walls, and floor, respectively. Based on the room dimensions and surface reflectivities, the coefficient of utilization (CU) from the photometric report for this type of fixture is 0.72 .

Seven typical lighting retrofit alternatives are considered. These range from simply replacing the standard lamps with 34 watt lamps, to installing new electronic ballasts and T-8 lamps. The fixture type and spacing are assumed to remain the same for all retrofits. The specific retrofits are listed in Table 1. The lamps considered are either standard $40 \mathrm{~W}$ cool white (F40WT12), low wattage lamps (F34WT12) with improved color rendition, or the smaller diameter, rare-earth phosphored lamps (F32WT8). The ballasts considered are standard magnetic (STD MAG), energy efficient magnetic (EE $M A G)$, electronic rapid start (ELEC RS), or electronic instant start designed specifically for T8 lamps (ELEC IS). The lamps' rated lumens listed in the table are from the lamp manufacturers' catalogs. The lamp/ballast system ballast factors are estimated industry-average values.

To analyze the effects of these different retrofits, we describe here the basis of two methods for analyzing lighting retrofit performance. The first method represents the simplified procedure that might be performed by a typical energy or building manager trying to decide between different ballast and lamp retrofits. The second method, which is termed the application-specific method, requires a more exacting approach.

\section{Standard Simplified Analysis Method}

We begin with the premise that the well-informed specifier of lighting retrofit equipment has access to the typical manufacturer's performance data as well as the original photometric report for the fixtures to be retrofitted. The standard method for identifying the potential energy savings from a lighting retrofit is to use the lamp/ballast performance data reported in lamp and ballast catalogues. Ballast manufacturers typically report input power for a particular lamp/ballast combination based on ANSI test procedures that maintain an ambient temperature about the lamps of $25^{\circ} \mathrm{C}$. (A few manufacturers also list input power for a typical enclosed 4-lamp fixture, but this is the exception not the norm). The ballast factor, which characterizes system light output for the lamp/ballast combination, is often not given or may be ignored. For the standard method, we assume that the specifier uses the ballast factor to account for light level changes but uses the ANSI input watts for the estimate for fixture input power.

If practical, the specifier should consult the photometric report for the existing fixtures to estimate the light levels for the existing lighting system as a prelude to predicting postretrofit light levels. (Even if existing light levels are actually measured, it is still necessary to take account of the lumen maintenance effects of changing from an old, depreciated lighting system to a system with new lamps and cleaned fixtures). Using the dimensions of the room and the height of the lighted work plane, the coefficient of utilization (CU) is read from the report. The $\mathrm{CU}$ is the ratio of the lumens that intersect the workplane to the total lamp lumens in the ceiling system. Maintained light levels are then calculated from the $\mathrm{CU}$ using the following:

$$
\text { Illuminance }=\frac{C U \times \text { lumens } \times M F \times B F}{\text { area }}
$$

where MF is the maintenance factor, BF is the ballast factor and lumens is the total lamp lumens. The fixture's candlepower distribution, from which the $\mathrm{CU}$ is calculated in the photometric report, is measured with the fixture suspended in an ambient temperature of $25^{\circ} \mathrm{C}$. This standardized thermal environment causes the lamps to operate at a temperature somewhat higher than the temperature at which the lamps (and ballasts) are rated for lumen output. This means that the change in lumen output that rcsults from the lamps operating at a temperature higher than that at which they are rated will be captured by the standard photometric test procedure. But the standard procedure does not account for the fact that the lamps will be at still another, generally higher, temperature when the fixture is mounted in the application. Since fluorescent fixtures are often mounted in a ceiling plenum where the ambient temperature about the fixture is higher than $25^{\circ} \mathrm{C}$, one should multiply the numerator in the above equation by a thermal application factor TF. Because this factor is generally not known (or its need not understood), it is not considered in the simple analysis method.

In addition to the thermal factor for light output, the lamp ballast system will draw a different amount of power in the actual application than it will under photometric test conditions. While this difference in power is usually not as 
large as the difference in light output, it is not negligible in many applications.

These thermal application factors are not accounted for in the simple method but will be accounted for in the application specific method detailed below.

\section{Application Specific Analysis Methods}

In the application specific analysis method, we estimate application thermal factors to obtain a more refined estimate of lumen output and input power under application conditions. To do this, we have estimated the lamp ambient tcmperature for each of several retrofit options and used these estimates as input to the LEAR spreadsheet program [4]. LEAR uses lamp/ballast performance data from $[1,2]$ as the basis for computing application specific thermal factors both with respect to light output and system input power.

\section{Lighting System HVAC Interactions}

Simplified analysis methods exist to estimate the reduction in cooling load that results from most lighting retrofits. A common method is based on the fraction of cooling that typically occurs in a given location and the cooling system efficiency [5]. An estimate of cooling energy savings is found by multiplying the cooling factor times the lighting energy savings divided by the cooling equipment COP. (This method is a refinement of the "rule-of-thumb" that states that every watt saved in lighting power is a third watt saved in the cooling load.) The cooling factor accounts for the fraction of the year in which cooling occurs and the fraction of the lighting load that is coincident with the lighting load. The method assumes that the cooling fraction is location dependent but independent of the air distribution system, HVAC controls, and building type, that $90 \%$ of the light load is coincident with the cooling load, and that the rated chiller COP is a close approximation to the weighted average system COP. A similar method also exists to predict the additional heating requirement resulting from the lighting retrofit. For this calculation, the heating fraction is fraction of the year with no cooling and the coincident load is assumed to be $20 \%$.

To more accurately predict the effect the retrofits have on the office cooling and heating system, we have modeled four different building configurations using the DOE-2.1D computer simulation program. The DOE-2 program predicts the hourly energy performance of a building given hourly weather information and a description of the building and its equipment. The four configurations examined are:

1) an older building located in Chicago, Illinois with a reheat fan system (RHFS) having coolant supplied by a centrifugal chiller and heat supplied by a gas boiler

2) an older building in Charleston, South Carolina with the same system as in 1
3) a newer building located in Chicago with a variable air volume (VAV) system with coolant supplied by a centrifugal chiller and heat supplied by a gas boiler

4) a newer building in Charleston with the same system as 3 . The Chicago and Charleston locations were selected since they have been found to represent the population weighted average of a northern U.S. and a southern U.S. climate [6]. The buildings modeled in the program have 8 stories and 160,000 square feet of floor area. Their shell characteristics are based on the 1983 Nonresidential Building Energy Consumption Survey [7]. From the raw survey data, the characteristics have been aggregated for large offices buildings in the north or south built before or after 1980. Thus the shell characteristics in the four buildings vary slightly, there is more insulation in the new buildings than the old buildings, and more insulation in the North than in the South. The occupancy and equipment operation scheduling and building models have been adopted from previous commercial building prototype studies [8].

To account for the different light levels of the different technologies, the lighting power density in the building model was changed to match the base and retrofit cases (based on the application performance data lpd values). The lighting schedule maintained $20 \%$ of the lights on during off hours and $90 \%$ of the lights on from 7 am to 6 pm during weekdays. This amounts to all the lights being on 3693 hours in the year. In the building models, the percent of the heat flowing from the lights to the conditioned space is 45 . The remaining heat is picked up by the HVAC system return air stream in the plenum The heat-to-space value is appropriate for nonvented recessed fixtures and is based on experimental testing conducted by the National Institute of Standards and Technology [9]. The energy values presented in the table are the energy consumed by the chiller and the boiler, they are not cooling and heating loads. These values from the DOE-2 output have been scaled to represent energy used by the 5000 $\mathrm{ft}^{2}$ office.

\section{RESULTS}

The results of the analysis for the seven retrofits considered are presented in Table 1. Two estimates of system performance are shown. The first is based on the standard method of prediction, the other on application specific performance data. Using the ANSI system input power always predicts more lighting power consumed than the application specific method, particularly when calculating the power use of the original lighting system, i.e., the basecase. Overestimating the energy use of the basecase causes a large relative error $(55 \%)$ in predicting the energy savings for the simple re-lamping retrofit (RETRO 1) -- the retrofit that causes the least significant reduction in lighting power density with a $20 \%$ reduction in maintained light level. RETRO 7 on the other hand, (T8 lamps/electronic instant start ballasts) 
TABLE I.

STANDARD AND APPLICATION SPECIFIC RETROFIT ANALYSIS

\begin{tabular}{|c|c|c|c|c|c|c|c|c|}
\hline Retrofit Label & Base & Retro 1 & Retro 2 & Retro 3 & Retro 4 & Retro 5 & Retro 6 & Retro 7 \\
\hline \multicolumn{9}{|l|}{ Lamp/Ballast Description } \\
\hline Lamp & F40WT12 & F34WT12 & F40WT12 & F34WT12 & F32WT8 & F40WT12 & F34WT12 & F32WT8 \\
\hline Rated Lumens & 3050 & 2800 & 3200 & 2800 & 2900 & 3200 & 2800 & 2900 \\
\hline Ballast & STD MAG & STD MAG & EE MAG & EE MAG & EE MAG & ELEC RS & ELEC RS & ELEC IS \\
\hline Ballast Factor & 0.95 & 0.88 & 0.94 & 0.87 & 0.94 & 0.88 & 0.85 & 0.95 \\
\hline \multicolumn{9}{|l|}{ Standard Performance } \\
\hline $\mathrm{CU}$ & 0.72 & 0.72 & 0.72 & 0.72 & 0.72 & 0.72 & 0.72 & 0.72 \\
\hline Maint. Light Level ( $f c)$ & 64 & 54 & 66 & 54 & 60 & 62 & 52 & 61 \\
\hline Watts (at $25^{\circ} \mathrm{C}$ ) & 192 & 164 & 172 & 144 & 140 & 156 & 120 & 124 \\
\hline Power Density (W/ft $\left.{ }^{2}\right)$ & 1.73 & 1.48 & 1.55 & 1.30 & 1.26 & 1.40 & 1.08 & 1.12 \\
\hline Savings (W/fixture) & 0 & 28 & 20 & 48 & 52 & 36 & 72 & 68 \\
\hline \multicolumn{9}{|l|}{ Application Performance } \\
\hline Correction Factor & 0.94 & 0.94 & 0.96 & 0.95 & 0.96 & 0.97 & 0.96 & 0.96 \\
\hline Corrected CU & 0.67 & 0.68 & 0.69 & 0.69 & 0.69 & 0.70 & 0.69 & 0.69 \\
\hline Footcandles & 60 & 51 & 63 & 51 & 58 & 60 & 51 & 58 \\
\hline Watts (at $T_{a p p}$ ) & 174 & 156 & 156 & 137 & 129 & 145 & 116 & 111 \\
\hline Power Density $\left(\mathrm{W} / \mathrm{ft}^{2}\right)$ & 1.57 & 1.40 & 1.40 & 1.23 & 1.16 & 1.31 & 1.04 & 1.00 \\
\hline Savings (W/fixlure) & 0 & 18 & 18 & 37 & 45 & 29 & 58 & 63 \\
\hline \multicolumn{9}{|l|}{ Ycarly Savings" ( $k$ Wh/Year) } \\
\hline Standard Analysis & 0 & 4653 & 3324 & 7977 & 8642 & 5983 & 11965 & 11301 \\
\hline Application Specific Anlysis & 0 & 2991 & 2991 & 6149 & 7478 & 4819 & 9639 & 10470 \\
\hline
\end{tabular}

a Lights on 3693 hours per year

reduces lighting power density from $1.57 \mathrm{w} / \mathrm{ft}^{2}$ (in the basecase) to $1 \mathrm{w} / \mathrm{ft}^{2}$ with only an insignificant reduction in maintained light levels even when estimated using the more exact method.

Table 2 presents the HVAC energy savings/loss as predicted by the quick calculation method described earlier (labcled "estimated" in the table) and as predicted from the DOE-2 simulation runs. The estimated effect on the HVAC system is based on the standard lighting performance data. Note that the cooling savings predicted with the simplified method shows reasonable similarity to the DOE-2 calculated values for the RHFS systems but show sizable discrepancies for the VAV systems. It is also significant that the standard method predicts smaller heating loss penalties for the retrofits than the DOE-2 calculation method.For comparative purposes, the units of gas consumption by the boiler is presented in kWh and not in BTUs. As shown in the table, the heating energy loss may be greater than the cooling energy saved. This is particularly true of the Chicago building. Since the price of gas per unit energy is much less than the price of electricity per unit energy, making up lost heat with gas is less expensive. But for HVAC systems employing electric heat, increased heating may take away from the lighting energy savings. The gas heating system efficiency is about .72 for each of the four buildings analyzed. Multiplying the reported heating energy lost values by the gas system efficiency gives a general idea of the additional heating required for an electric system.

Table 3 presents economic analyses of the lighting retrofits. The cost of energy is based on 1988 average commercial costs of $\$ .072 / \mathrm{kWh}$ for electricity and $\$ .017 / \mathrm{kWh}$ for gas. The dollar savings calculated from standard analysis are compared to the savings determined from the application specific analysis and the DOE-2 HVAC analysis. The reported equipment costs are based on estimates from local distributors. The retrofit capital costs are determined over the life of the replacement ballast, assumed to be twelve years. Lamp life is approximated at 4 years. Thus retrofit cost includes the incremental cost of the ballast and three sets of lamps. Simple payback is found by dividing the retrofit cost by the anticipated yearly cost savings.

Table 3 indicates that the total retrofit savings (lighting energy saved plus reduction in HVAC energy) in terms of cost/year, are typically overestimated by about $20 \%$ using the simplified method of calculation compared to the more detailed calculation method. It is also significant that cost 
TABLE I.

DETAILED AND SLMPLE HVAC INTERACTION ANALYSIS

\begin{tabular}{|c|c|c|c|c|c|c|c|c|}
\hline Retrofit Label & Base & Retro 1 & Retro 2 & Retro 3 & Retro 3 & Retro 5 & Retro 6 & Retro 7 \\
\hline \multicolumn{9}{|l|}{ DOE-2 Cooling Energy $(\mathrm{kWh} / \mathrm{yr})^{\mathrm{a}}$} \\
\hline DOE2-Chicago, RHFS & 18909 & 18540 & 18540 & 18137 & 18024 & 18345 & 17769 & 17684 \\
\hline DOE2-Chicago, VAV & 7124 & 6942 & 6942 & 6762 & 6684 & 6847 & 6551 & 6506 \\
\hline DOE2-Charleston, RHFS & 22316 & 21724 & 21724 & 21145 & 20909 & 21417 & 20504 & 20369 \\
\hline DOE2-Charleston, VAV & 13821 & 13394 & 13394 & 12970 & 12797 & 13169 & 12502 & 12403 \\
\hline \multicolumn{9}{|l|}{ DOE-2 Cooling Savings (kWh/yr) } \\
\hline DOE2-Chicago, RHFS & 0 & 369 & 369 & 772 & 885 & 564 & 1140 & 1225 \\
\hline DOE2-Chicago VAV & 0 & 182 & 182 & 362 & 440 & 277 & 573 & 618 \\
\hline DOE2-Charleston, RHFS & 0 & 592 & 592 & 1171 & 1407 & 899 & 1812 & 1947 \\
\hline DOE2-Charleston, VAV & 0 & 427 & 427 & 851 & 1024 & 652 & 1319 & 1418 \\
\hline \multicolumn{9}{|l|}{ Estimated Cooling Savings $(\mathrm{kWh} / \mathrm{yr})^{\mathrm{b}}$} \\
\hline Estimated-Chicago RHFS & 0 & 391 & 280 & 671 & 727 & 503 & 1007 & 951 \\
\hline Estimated-Chicago VAV & 0 & 432 & 308 & 740 & 802 & 555 & 1110 & 1048 \\
\hline Estimated-Charleston RHFS & 0 & 690 & 493 & 1183 & 1282 & 888 & 1775 & 1676 \\
\hline Estimated.Charleston VAV & 0 & 743 & 531 & 1274 & 1381 & 956 & 1912 & 1805 \\
\hline \multicolumn{9}{|l|}{ DOE-2 Heating Energy $(\mathrm{kWh} / \mathrm{yr})^{c}$} \\
\hline DOE2-Chicago, RHFS & 91201 & 93158 & 93158 & 94426 & 94962 & 93827 & 95880 & 96816 \\
\hline DOE2-Chicago, VAV & 46194 & 47244 & 47244 & 48338 & 48761 & 47828 & 49486 & 49728 \\
\hline DOE2-Charleston, RHFS & 46301 & 46847 & 46847 & 47387 & 47623 & 47131 & 48027 & 48162 \\
\hline $\begin{array}{c}\text { DOE2-Charleston, VAV } \\
\text { DOE-2 Heating Load Loss ( } k \text { Wh/yr }\end{array}$ & 19882 & 20380 & 20380 & 20893 & 21114 & 20650 & 21492 & 21618 \\
\hline DOE2-Chicago, RHFS & 0 & -1257 & -1257 & .2525 & -3061 & .1926 & .3979 & -4915 \\
\hline DOE2-Chicago VAV & 0 & .1050 & -1050 & -2144 & -2567 & -1634 & -3292 & -3534 \\
\hline DOE2-Charleston, RHFS & 0 & .546 & .546 & -1086 & -1322 & .830 & -1726 & -1861 \\
\hline DOE2-Charleston, VAV & 0 & .498 & -498 & -1011 & -1232 & .768 & -1610 & -1736 \\
\hline \multicolumn{9}{|l|}{ Estimated Heating Savings $(\mathrm{kWh} / \mathrm{yr})^{\mathrm{d}}$} \\
\hline Estimated-Chicago RHFS & 0 & .762 & .545 & -1307 & -1416 & .980 & -1961 & -1852 \\
\hline Estimated-Chicago VAV & 0 & .752 & .537 & -1289 & -1397 & .967 & .1934 & -1827 \\
\hline Estimated-Charleston RHFS & 0 & .415 & .296 & .711 & .771 & .534 & -1067 & -1008 \\
\hline Estimated-Charleston VAV & 0 & .403 & .288 & -691 & .749 & .519 & .1037 & -979 \\
\hline
\end{tabular}

a Energy consumption by centrifugal chiller

${ }^{b}$ COP chi, RHFS $=4.3 ;$ COP chi, $V A V=3.9 ;$ COP cha, RIHFS $=4.2 ;$ COP cha, vav $=3.9$

c Energy consumption by gas boiler

${ }^{d}$ Gas boiler system efficiency Chi,RHFS $=0.73$; eff Chi, VAV $=0.74$; eff Cha,RHFS $=0.69$; eff Cha,VAV $=0.71$

savings estimated using the simplified method and ignoring HVAC effects altogether also overestimates the retrofit energy savings compared to the detailed method. Also remarkable is the fact that the cost savings calculated using application specific method but ignoring HVAC effects corresponds reasonably well with the application specific method that includes detailed HVAC calculations.

\section{DISCUSSION}

Our results indicate that estimates of lighting energy use based on standard lighting performance data overestimate the actual lighting energy savings compared to a method that takes into account thermal and component interaction effects. In fact, the largest source of error is the use of the rated input power (192 watts) for the basecase instead of an application specific value (174 watts).

The fact that lighting power densities based on the application specific data are notably less than standard values, has implications for sizing the HVAC system as well. If higher values for lighting power density are used for HVAC design calculations, then oversized systems may be specified. This error is made worse by assuming that all of the heat from the lights contribute to the zone internal gains. Tests 
TABLE III.

RETROFIT ECONOMIC ANALYSIS

\begin{tabular}{|c|c|c|c|c|c|c|c|c|}
\hline Retrofit Label & Base & Retro 1 & Retro 2 & Retro 3 & Retro 4 & Retro 5 & Retro 6 & Retro 7 \\
\hline \multicolumn{9}{|c|}{ Standard Analysis Operating Cost Savings (SYYear) } \\
\hline $\begin{array}{l}\text { Lighting System Savings } \\
\text { Cooling System Savings }{ }^{a}\end{array}$ & 0 & 335 & 239 & 574 & 622 & 431 & 862 & 814 \\
\hline Chicago, RHFS & 0 & 28 & 20 & 48 & 52 & 36 & 72 & 68 \\
\hline Chicago VAV & 0 & 31 & 22 & 53 & 58 & 40 & 80 & 75 \\
\hline Charleston, RHFS & 0 & 50 & 36 & 85 & 92 & 64 & 128 & 121 \\
\hline Charleston, VAV & 0 & 54 & 38 & 92 & 99 & 69 & 138 & 130 \\
\hline \multicolumn{9}{|l|}{ Heating System Savings ${ }^{b}$} \\
\hline Chicago, RHFS & 0 & -13 & .9 & -22 & -24 & -17 & -33 & -31 \\
\hline Chicago VAV & 0 & -13 & -9 & .22 & -24 & -16 & -33 & -31 \\
\hline Charleston, RHFS & 0 & -7 & -5 & -12 & -13 & -9 & -18 & -17 \\
\hline Charleston, VAV & 0 & .7 & -5 & -12 & -13 & -9 & -18 & -17 \\
\hline \multicolumn{9}{|l|}{ Total Retrofit Savings } \\
\hline Chicago, RHFS & 0 & 350 & 250 & 600 & 650 & 450 & 901 & 851 \\
\hline Chicago VAV & 0 & 353 & 252 & 606 & 656 & 454 & 909 & 858 \\
\hline Charleston, RHFS & 0 & 378 & 270 & 647 & 701 & 486 & 971 & 917 \\
\hline Charleston, VAV & 0 & 382 & 273 & 654 & 709 & 491 & 982 & 927 \\
\hline \multicolumn{9}{|c|}{ Application Specific Operating Cost Savings ( $\$$ Year) } \\
\hline Lighting System Savings & 0 & 215 & 215 & 443 & 538 & 347 & 694 & 754 \\
\hline \multicolumn{9}{|l|}{ Cooling System Savings ${ }^{a}$} \\
\hline Chicago, RHFS & 0 & 27 & 27 & 56 & 64 & 41 & 82 & 88 \\
\hline Chicago VAV & 0 & 13 & 13 & 26 & 32 & 20 & 41 & 44 \\
\hline Charleston, RHFS & 0 & 43 & 43 & 84 & 101 & 65 & 130 & 140 \\
\hline Charleston, VAV & 0 & 31 & 31 & 61 & 74 & 47 & 95 & 102 \\
\hline \multicolumn{9}{|l|}{ Heating System Savings b } \\
\hline Chicago, RHFS & 0 & -21 & .21 & -43 & -52 & .33 & -68 & -84 \\
\hline Chicago VAV & 0 & -18 & -18 & -36 & -44 & -28 & .56 & .60 \\
\hline Charleston, RHFS & 0 & -9 & .9 & -18 & -22 & -14 & .29 & -32 \\
\hline Charleston, VAV & 0 & -7 & .5 & -12 & -13 & -9 & -18 & -17 \\
\hline \multicolumn{9}{|l|}{ Total Retrofit Savings } \\
\hline Chicago, RHFS & 0 & 221 & 221 & 455 & 550 & 355 & 708 & 758 \\
\hline Chicago VAV & 0 & 211 & 211 & 432 & 526 & 339 & 679 & 738 \\
\hline Charleston, RHFS & 0 & 249 & 249 & 509 & 617 & 398 & 795 & 862 \\
\hline Charleston, VAV & 0 & 239 & 241 & 492 & 599 & 385 & 771 & 839 \\
\hline \multicolumn{9}{|l|}{ Retrofit Costs (\$) } \\
\hline Lamp & 1.88 & 2.50 & 1.88 & 2.50 & 1.80 & 1.88 & 2.50 & 1.88 \\
\hline Ballast & 0 & 0 & 12 & 12 & 12 & 22 & 22 & 22 \\
\hline Ballast Replacement Cost & 0 & 0 & 13 & 13 & 13 & 13 & 13 & 13 \\
\hline Cost Over Ballast Life ${ }^{c}$ & 0 & 112 & 1250 & 1362 & 1236 & 1750 & 1862 & 1750 \\
\hline \multicolumn{9}{|l|}{ Simple Payback (yr) } \\
\hline Standard Analysis (w/o HVAC) & $\mathrm{NA}$ & 0.3 & 5.2 & 2.4 & 2.0 & 4.1 & 2.2 & 2.2 \\
\hline \multicolumn{9}{|c|}{ Standard Analysis ( $w /$ estimated HVAC) } \\
\hline Chicago, RHFS & NA & 0.3 & 5.0 & 2.3 & 1.9 & 3.9 & 2.1 & 2.1 \\
\hline Chicago VAV & NA & 0.3 & 5.0 & 2.2 & 1.9 & 3.9 & 2.0 & 2.0 \\
\hline Charleston, RHFS & NA & 0.3 & 4.6 & 2.1 & 1.8 & 3.6 & 1.9 & 1.9 \\
\hline Charleston, VAV & NA & 0.3 & 4.6 & 2.1 & 1.7 & 3.6 & 1.9 & 1.9 \\
\hline $\begin{array}{l}\text { App Specific (w/o DOE2 HVAC) } \\
\text { App Specific (w/ DOE2 HVAC) }\end{array}$ & NA & 0.5 & 5.8 & 3.1 & 2.3 & 5.0 & 2.7 & 2.3 \\
\hline Chicago, RHFS & NA & 0.5 & 5.7 & 3.0 & 2.2 & 4.9 & 2.6 & 2.3 \\
\hline Chicago VAV & NA & 0.5 & 5.9 & 3.1 & 2.3 & 5.2 & 2.7 & 2.4 \\
\hline Charleston, RHFS & NA & 0.4 & 5.0 & 2.7 & 2.0 & 4.4 & 2.3 & 2.0 \\
\hline Charleston, VAV & $\mathrm{NA}$ & 0.5 & 5.2 & 2.8 & 2.1 & 4.5 & 2.4 & 2.1 \\
\hline
\end{tabular}

1988 average commercial electricity cost $=\$ 0.72 / \mathrm{kWh}$

b 1988 average commercial gas cost $=\$ 0.017 / \mathrm{kWh}$

${ }^{c}$ Increased costs over the base system with lamps replaced two times in the $12 \mathrm{yr}$ ballast life 
have shown for recessed fixtures that about half the heat actually affects the zonal temperature while the other half is picked up by the return air stream via the plenum. The HVAC systems in the DOE-2 analysis were sized automatically by the program. Consequently, their system efficiencies may be slightly higher than that of oversized systems typically used in buildings. The VAV systems used less energy than the RHF systems but they operated more at part load resulting in a lower COP. These COPs are used in the simplified cooling savings calculations, making it a more system specific evaluation than normal.

From the DOE-2 HVAC analysis, generally more heating HVAC energy is lost than cooling energy saved. Although significant for an energy accounting point of view, the low cost of gas makes it insignificant in the economic analysis. But for an electrically heated building, the additional heat used would detract from the cooling savings and possibly the lighting savings.

\section{CONCLUSION}

Using application factors to determine light output and power input provides a more rigorous approach to calculating retrofit savings than using standard performance assumptions and simplified HVAC interaction approximations. Using standard lighting analysis methods results in an overprediction of retrofit energy savings in all applications examined. Taking an additional credit for decreased cooling without considering the increased heating penalty, exacerbates the overprediction.

In general, for large buildings without electric heat, analyzing lighting retrofits using application specific performance data but ignoring HVAC effects gives a very reasonable estimate of the total building savings in northern climates. For the southern climates, which have higher cooling loads, the application specific method will produce conservative estimates of the energy savings. Thus, if one uses application specific performance data to estimate lighting energy savings in large buildings, one can predict the energy savings reasonably accurately without going to the trouble of doing an additional detailed calculation of HVAC effects.

In the buildings modeled, the additional heating energy was almost equal to the cooling energy saved in the southern climate. The northern climate heating energy deficit outweighed the cooling gain by three to four times. This is significant for energy forecasting models that track total energy use and for the analysis of buildings with electric heat.

\section{ACKNOWLEDGMENTS}

This work was supported by the Assistant Secretary for Conservation and Renewable Energy, Office of Building Technolugies, Building Equipment Division and the Deputy Undersecretary of the Office of Policy, Planning, and Analysis through the U.S. Department of Energy under Contract No. DE-AC03-76SF00098.

\section{REFERENCES}

[1] Siminovitch, M., F. Rubinstein and R. Verderber, "Determining lamp/ballast system performance with a temperature-controlled integrating chamber," Journal of the Illuminating Engineering Society, vol. 14, no. 1, October 1984, pp. 364-378.

[2] Bleeker, N., and W. Veenstra, "The performance of four foot fluorescent lamps as a function of ambient temperatures on $60 \mathrm{~Hz}$ and high frequency ballasts," Proceedings of the 1990 Annual IES Conference, Baltimore, August 1990.

[3] Lewin, I, "Performance characteristics of fluorescent lamp and ballast combinations," Journal of the Illuminating Engineering Society, vol. 13, no. 1, October 1983, pp. $162-173$.

14] Rubinstein, F., and C. Zhang, "A spreadsheet for analyzing the in situ performance of fluorescent luminaires," Proceedings of the 1991 Annual IES Conference, Montrcal, August 1991.

[5] Mendelsohn, C., "Saving energy twice: the lighting/air conditioning domino effect," Proceedings of GlobalCon -Lighting Energy Congress 1992 . San Jose, CA, March 1992.

[6] Andersson, B., W. Carroll, and M. Martin, "Aggregation of U.S. population centers using climate parameters related to building energy use," Journal of Climate and Applied Meterology, vol. 25, no. 5, p. 596.[5] U.S. Department of Energy, Annual Energy Review 1990, EIA, DOE/EIA0384(90), May 1991, p. 69.

[7] U.S. Department of Energy, Nonresidential Buildings Energy Consumption Survey 1983, EIA, DOE/EIA. 0246(83).

[8] Huang, J., H. Akbari, L. Rainer, and R. Ritschard, "481 Prototypical commercial buildings for 20 urban market areas," Lawrence Berkeley Laboratory for the Gas Rescarch Institute, LBL-29798, April 1991.

[9] Treado, S., and J. Bean, "The interaction of lighting, heating, and cooling systems in buildings -interim report," National Institute of Standards and Technology, NISTIR 88 3860, Sept. 1988. 

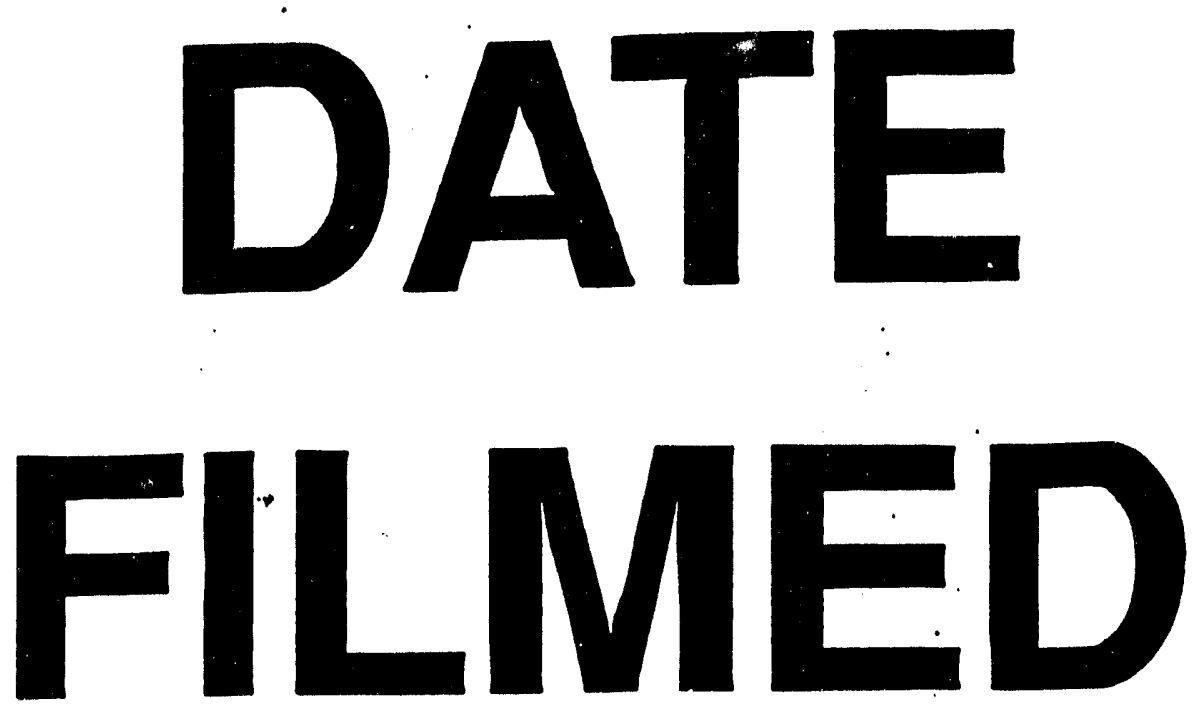

$1 / 11 / 94$
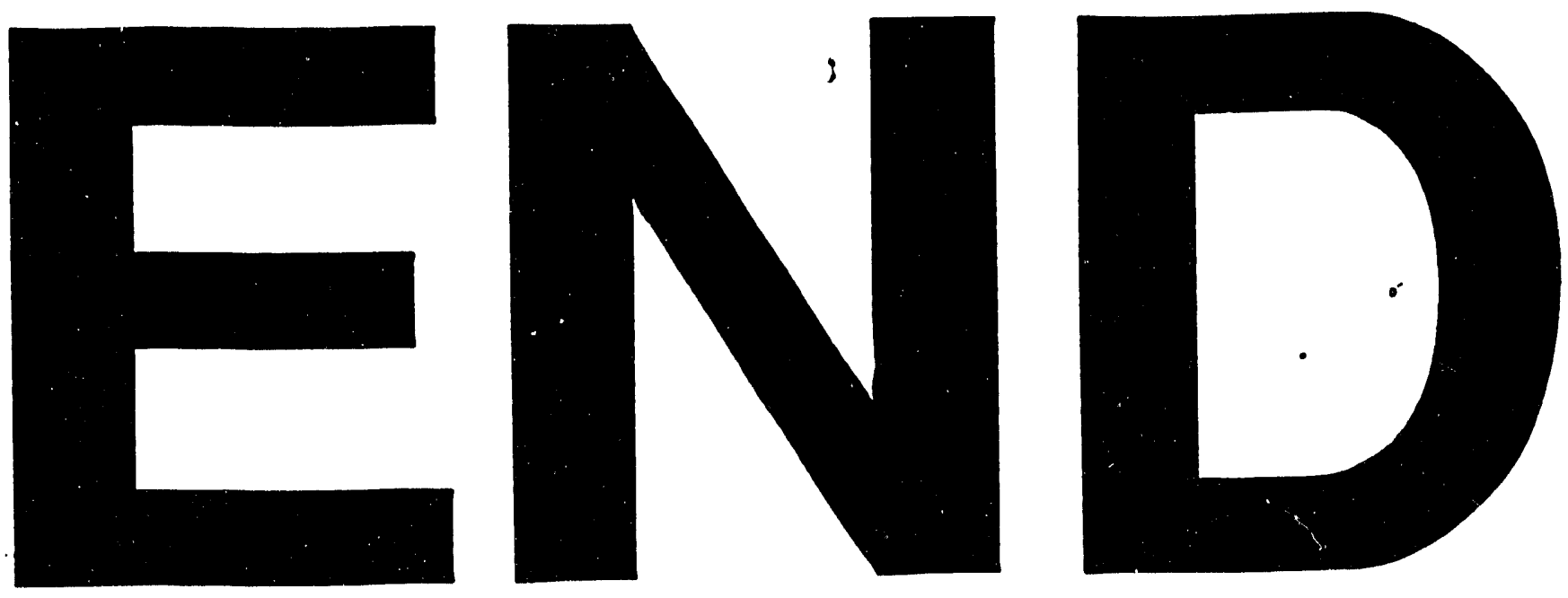
